\title{
UM PANORAMA SOBRE OS ESTUDOS RELACIONADOS AO CONFORTO TÉRMICO EM SALAS DE AULA
}

\section{A SCENERY ABOUT STUDIES RELATED TO THERMAL COMFORT IN CLASSROOMS}

\author{
Nilmar Luís Arenhardt E-mail: nilmarluis82@gmail.com \\ Paulo Roberto Wander* E-mail: prwander@unisinos.br \\ *Universidade do Vale do Rio dos Sinos (UNISINOS), São Leopoldo - RS
}

Resumo: Este trabalho objetiva analisar as características das publicações sobre conforto térmico em salas de aula nas bases de dados Scopus e Web of Science (WOS), identificando as principais fontes, os principais autores e algumas particularidades sobre a produção científica deste tema. $O$ estudo compreende uma revisão bibliográfica que foi realizada a partir de uma pesquisa bibliométrica, na qual por meio de uma análise estatística foi possível mapear e gerar alguns indicadores para o tratamento da informação, constituindo assim, uma abordagem quantitativa e qualitativa. Na base Scopus, foram encontradas 231 publicações relacionadas e na WOS, 135 publicações. Os resultados comparativos mostraram que o número de trabalhos relacionados ao conforto térmico em salas de aula aumentou consideravelmente na última década. Verificou-se que a China é o país com o maior número de publicações. O Brasil surge na $12^{\underline{a}}$ posição na base Scopus e na $10^{a}$ posição na base WOS. Também verificou-se a importância do periódico Building and Environment para o tema e que para as salas de aula e ambientes de estudo, há uma estreita relação entre os tópicos conforto térmico, ventilação e qualidade do ar interno, uma vez que estes podem interferir consideravelmente no rendimento e na saúde dos alunos.

Palavras-chave: Conforto térmico. Ensino. Sala de aula. Bibliometria.

\begin{abstract}
This study aims to analyze the characteristics of publications about thermal comfort in classrooms at the Scopus and Web of Science (WOS) databases, identifying the main sources, the main authors and some peculiarities of the scientific production about this theme. The study comprised a bibliographical review that was carried out from a bibliometric research, in which through a statistical analysis it was possible to map and generate some indicators for information treatment, thus constituting a quantitative and qualitative approach. In Scopus database, 231 related publications were found and 135 publications in WOS database. The comparative results showed that the number of researches related with thermal comfort in classrooms increased considerably in the last decade. It was verified that in the publications ranking, China is the country with larger number of publications. Brazil comes in 12th position at Scopus database and in 10th at WOS database. The importance of the Building and Environment journal for the subject was also verified and that for the classrooms and study environments there is a close relationship between the topics thermal comfort, ventilation and internal air quality, since these can interfere considerably on the efficiency and health of students.
\end{abstract}

Keywords: Thermal comfort. Education. Classroom. Bibliometrics. 


\section{INTRODUÇÃO}

As discussões relacionadas ao conforto térmico dos ambientes são cada vez mais recorrentes em diferentes contextos e em diferentes áreas do conhecimento, ultrapassando as fronteiras da área da engenharia.

Historicamente, o homem sempre procurou o seu bem estar e o conforto e à medida que novas e acessíveis tecnologias surgem, faz com que sejam buscadas sempre melhores condições ambientais e melhor qualidade de vida. Conforme Frota e Schiffer (2003, p.17), "O homem tem melhores condições de vida e de saúde quando seu organismo pode funcionar sem ser submetido à fadiga ou estresse, inclusive térmico". Independentemente do ambiente, o conforto térmico tem um efeito muito significativo no bem estar das pessoas. Ao se analisar um local de trabalho, por exemplo, verificase que um desconforto térmico pode refletir diretamente no rendimento de um trabalhador. Barbhuiya e Barbhuiya (2013) comentam que por ser um fator psicológico, o conforto térmico pode afetar o moral dos ocupantes de determinado ambiente, prejudicando a comodidade e a produtividade.

Recentemente, houve um aumento do número de pesquisas relacionadas ao conforto térmico em salas de aula, ao que tudo indica isso se deve aos mesmos motivos que se discutem questões deste tema em demais ambientes como indústria, escritórios e prédios comercias ou mesmo residências e conjuntos habitacionais. Em relação às edificações de instituições de ensino, mais precisamente às salas de aula, Krüger e Zannin (2004) lembram que os projetistas e construtores devem estar cientes de que fatores ambientais do próprio prédio ou edifício vão afetar no processo de ensino e aprendizagem. Para os autores, o desconforto térmico nestes ambientes, como por exemplo salas de aula superaquecidas ou excessivamente frias, pode ser associado ao estresse físico (estresse térmico) e, portanto, ser responsável por indisposições e mau desempenho escolar dos alunos. Ainda em relação a este tema, Barbhuiya e Barbhuiya (2013) comentam que o conforto térmico em edifícios destinados ao ensino, em particular, é de extrema importância. Isso ocorre porque o desconforto térmico em tais construções pode criar condições insatisfatórias, tanto para funcionários quanto para alunos, o que pode se tornar uma distração para os ocupantes do ambiente, que ficam suscetíveis à redução de produtividade e de desempenho. 
Diante desse contexto torna-se importante ampliar o conhecimento referente ao tema conforto térmico em salas de aula. O presente estudo tem como objetivo geral analisar as características das publicações sobre conforto térmico em salas de aula nas bases de dados Scopus e Web of Science (WOS) e tem como objetivos específicos: identificar as principais fontes, os principais autores e algumas particularidades sobre a produção científica deste tema.

Este trabalho está estruturado em cinco seções: A introdução é a primeira seção, a segunda apresenta a contextualização teórica sobre o conforto térmico nas salas de aula, a terceira seção trata do método do estudo. Logo após, apresenta-se a análise e discussão dos resultados. Por fim, apresentam-se as considerações finais da pesquisa.

\section{CONFORTO TÉRMICO NAS SALAS DE AULA}

A ASHRAE (American Society of Heating, Refrigerating and Air-Conditioning Engineers) define o conforto térmico como o estado de espírito que expressa satisfação com o ambiente térmico (ASHRAE 55, 2013). O conforto térmico ocorre quando a temperatura do corpo é mantida dentro de estreitos limites, quando a umidade da pele é baixa e o esforço fisiológico de regulação de temperatura é minimizado (ASHRAE, 2009).

O conforto térmico de um indivíduo está relacionado às trocas de calor com 0 ambiente, sendo que essas trocas podem ser equacionadas através do balanço térmico de uma pessoa. A norma ISO 7730/2005 define que o balanço térmico é obtido quando a produção interna de calor pelo corpo é igual a perda de calor para o ambiente. Em um ambiente moderado, o sistema termorregulador tentará automaticamente modificar a temperatura da pele e a secreção de suor para manter o equilíbrio térmico.

De acordo com Frota e Schiffer (2003), a noção do conforto térmico é diretamente relacionada à necessidade de manutenção da temperatura interna do corpo em valores razoavelmente constantes, por volta de $37^{\circ} \mathrm{C}$ - fator essencial à saúde e ao bem-estar. Quando não é exigido um maior esforço para a troca de calor entre o corpo humano e o ambiente, o indivíduo tem a sensação de conforto térmico, consequentemente a capacidade de trabalho, por este ponto de vista, é máxima. 
Por outro lado, se as condições térmicas ambientais causam a sensação de frio ou de calor é porque nosso organismo está perdendo mais ou menos calor do que o necessário para a manutenção da temperatura interna. Nestas condições, a homeotermia passa a ser alcançada com um esforço adicional, o que representa uma sobrecarga ao organismo e que ocasiona a queda de rendimento do indivíduo e em casos excepcionais até a perda total da capacidade ou mesmo um problema de saúde.

De acordo com Lamberts, Dutra e Pereira (2014), nos anos 70 o dinamarquês Povl Ole Fanger derivou uma equação geral para o conforto térmico, de forma a avaliar a combinação de algumas variáveis, são elas: a temperatura do ar, a temperatura radiante, a umidade relativa e a velocidade do ar. Além destas variáveis ambientais, a taxa metabólica e a vestimenta também influenciam na sensação de conforto térmico de uma pessoa. Através de um trabalho experimental, Fanger obteve o Voto Médio Predito - PMV (Predicted Mean Vote), que consiste em um valor numérico que demonstra a sensibilidade humana ao frio e ao calor.

A partir destes estudos, surgiu também o conceito de Porcentagem de Pessoas Insatisfeitas - PPD (Predicted Percentage of Dissatisfied). Atualmente a norma ISO $7730 / 2005$ adota as pesquisas de Fanger e recomenda que em espaços, termicamente moderados, de ocupação humana, o índice PPD deve ser menor que 10\%, o que corresponde a uma faixa do PMV de $-0,5 \mathrm{a}+0,5$.

Outra questão importante relacionada ao conforto térmico é o calor gerado pelo organismo através do metabolismo. Dependendo da atividade física desenvolvida pelo indivíduo, maior ou menor será o calor gerado. Lamberts, Dutra e Pereira (2014) lembram que é importante a um arquiteto, por exemplo, conhecer a função de sua arquitetura, consequentemente poderá prever o nível de atividade realizado em seu interior e, a partir daí, algumas premissas sobre a sensação de conforto térmico dos ocupantes deste ambiente.

Alguns estudos apontam que a produtividade e a qualidade do trabalho realizado por uma pessoa estão diretamente relacionadas com as condições do ambiente em que se desenvolvem as atividades e também que as condições térmicas adequadas podem influenciar positivamente nesta questão. Neste sentido, Coutinho Filho et al. (2007) mencionam que uma vez que exista esta relação direta da qualidade e da produtividade com o ambiente de trabalho podemos afirmar que as salas de aula precisam também fornecer aos alunos e professores condições saudáveis, no intuito 
de garantir a espontaneidade de umas das atividades mais importantes para a sociedade.

Assim como ocorre em ambientes de trabalho, professores e alguns alunos passam o maior período do dia em salas de aula e espaços de estudo. Corgnati, Filippi e Viazzo (2007) advertem que os alunos passam muito tempo ouvindo e compreendendo lições, situação na qual os mesmos permanecem em suas mesas, o que de certa forma limita a liberdade dos estudantes em poder modificar ou ajustar o seu nível de atividade de acordo com o ambiente térmico, durante o período de aula. Além disso, muitas vezes a possibilidade de abrir ou fechar janelas ou mesmo alterar parâmetros de funcionamento de sistemas de ventilação ou ar condicionado é restrita. Para Yatim et al. (2011), proporcionar um ambiente escolar confortável é essencial, pois pode afetar o ensino e a aprendizagem.

Nos últimos anos, vários estudos científicos analisaram os aspectos relacionados ao conforto térmico e a qualidade do ar interno em salas de aula. Algumas pesquisas inclusive avaliam a influência do ambiente térmico no desemprenho escolar de alunos.

Em seus estudos, Coutinho Filho et al. (2007) concluíram que a dificuldade de concentração e a inquietação são consequências de um ambiente que acarrete uma sensação térmica quente aos alunos e professores, afetando o desempenho escolar e profissional dos mesmos. Os autores comentam também que níveis incorretos de umidade relativa podem provocar sonolência e aumento do suor e que todos estes fatores quando não diagnosticados podem provocar estresse e, em caso de uma exposição prolongada nestes ambientes desfavoráveis, até doenças mais complexas. Batiz et al. (2009) verificaram em sua pesquisa que existe uma relação direta entre a atenção e a memória e a sensação de conforto térmico por parte dos estudantes. Quando os alunos encontram-se num ambiente termicamente adequado (sensação de conforto), a atenção e a memória permanecem inalteradas, consequentemente apresentam um bom desempenho.

Em outro estudo que analisa a influência das condições térmicas no desempenho escolar dos alunos, Sarbu e Pacurar (2015) mostraram que as condições do ambiente interior podem afetar fortemente a atuação dos alunos. Neste estudo, a performance máxima dos alunos foi obtida a uma temperatura de $27^{\circ} \mathrm{C}$, considerando a estação mais quente do ano, onde há a necessidade de refrigeração do ambiente. 
A pesquisa também mostrou que mesmo havendo um aumento notável de $87,5 \%$ na concentração de $\mathrm{CO}_{2}$ no ambiente analisado, a performance dos estudantes teve uma diminuição de apenas $0,6 \%$ durante os testes realizados, porém, esta pequena diminuição pode estar associada a uma duração relativamente curta dos testes.

Em sua pesquisa, Haverinen-Shaughnessy e Shaughnessy (2015) verificaram que houve uma associação estatisticamente significativa entre as taxas de ventilação das salas e os resultados obtidos em testes matemáticos aplicados a estudantes do ensino fundamental. Os pesquisadores concluíram que a manutenção de índices de ventilação e conforto térmico adequados nas salas de aula pode melhorar significativamente o desempenho acadêmico dos alunos.

\section{MÉTODO}

\subsection{Tipo de estudo e abordagem aplicada}

Esta revisão foi desenvolvida a partir de uma pesquisa bibliométrica, com 0 objetivo de ampliar o conhecimento referente às publicações relacionadas ao tema conforto térmico em salas de aula nas bases de dados WOS e Scopus. Segundo Guedes e Borschiver (2005), a bibliometria pode ser definida como uma ferramenta estatística que permite mapear e gerar diferentes indicadores de tratamento e gestão da informação e do conhecimento, com a qual é realizada uma análise quantitativa que possibilita minimizar a subjetividade inerente à indexação e recuperação das informações, produzindo conhecimento em determinada área de estudo.

Um fato conveniente é que as pesquisas bibliométricas podem fornecer subsídios importantes a futuros pesquisadores em determinada área de conhecimento ou assunto a ser analisado. Conforme Chueke e Amatucci (2015), os estudos bibliométricos podem auxiliar na tarefa de sistematizar as pesquisas realizadas num determinado campo de saber e propor problemas a serem investigados em pesquisas futuras.

Desta maneira, o estudo possui uma abordagem quantitativa na medida em que buscou quantificar algumas variáveis referentes à produção científica sobre conforto térmico em salas de aula e qualitativa na medida em que procurou analisar alguns tópicos relevantes ao tema. 


\subsection{Definição da amostra da pesquisa}

Os dados para a realização desta pesquisa foram coletados nas bases de dados WOS, do Institute for Scientific Information (ISI) e Scopus da Elsevier, durante o mês de janeiro de 2016.

Ambas as bases de dados indexam periódicos nas categorias (áreas): Ciências Biológicas, Ciências Exatas e da Terra, Ciências Ambientais, Ciências da Saúde, Ciências Agrárias, Engenharias, Ciências Sociais Aplicadas, Ciências Humanas, Linguística, Letras e Artes e Multidisciplinar.

A coleta de dados foi realizada a partir das estruturas de busca da WOS e da Scopus, com as palavras-chave: Conforto térmico, Universidade, Escola, Colégio, Colegial e Educacional (Thermal comfort, University, School, College, High school, Educational), sem delimitação de período, tipos de documentos ou áreas de conhecimento.

\subsection{Modelo conceitual da pesquisa}

Para proceder à análise bibliométrica o estudo buscou identificar as variáveis: total de publicações, ano das publicações, tipos de documentos, áreas temáticas, fontes das publicações, instituições, países, idiomas, autores e índices h ( $h$-index). O índice h foi proposto por Hirsch (2005), como sendo o número de artigos com um número de citações $\geq h$, e definido como um índice útil para caracterizar a produção científica de um pesquisador.

O índice h dá uma estimativa da importância, relevância e amplo impacto das contribuições cumulativas de pesquisas de um cientista, fornecendo um ponto de referência útil com o qual comparar, de forma imparcial, diferentes indivíduos competindo para o mesmo recurso quando um importante critério de avaliação é a produção científica (HIRSCH, 2005).

\section{ANÁLISE E DISCUSSÃO DOS RESULTADOS}

Os resultados desta pesquisa evidenciaram as principais características da produção científica relacionada ao tema conforto térmico em salas de aula. 
Primeiramente, foi realizada a pesquisa na base de dados Scopus, sendo encontradas 231 publicações. Posteriormente, foi realizada a pesquisa na base de dados WOS, sendo encontradas 135 publicações (considerando a principal coleção da Web of Science), obedecendo a estrutura que foi proposta para a realização das pesquisas em ambas as bases.

\subsection{Característica das publicações analisadas}

A seguir estão apresentadas as características gerais das publicações relacionadas ao tema, encontradas nas bases de dados Scopus e WOS conforme a divisão: ano das publicações, tipos de documentos, áreas temáticas, fontes das publicações, instituições, países, idiomas e autores.

\subsection{Número de publicações por ano}

A figura 1 apresenta a quantidade de publicações por ano, relacionadas com o tema conforto térmico em salas de aula na base Scopus.

Figura 1 - Publicações por ano na base Scopus

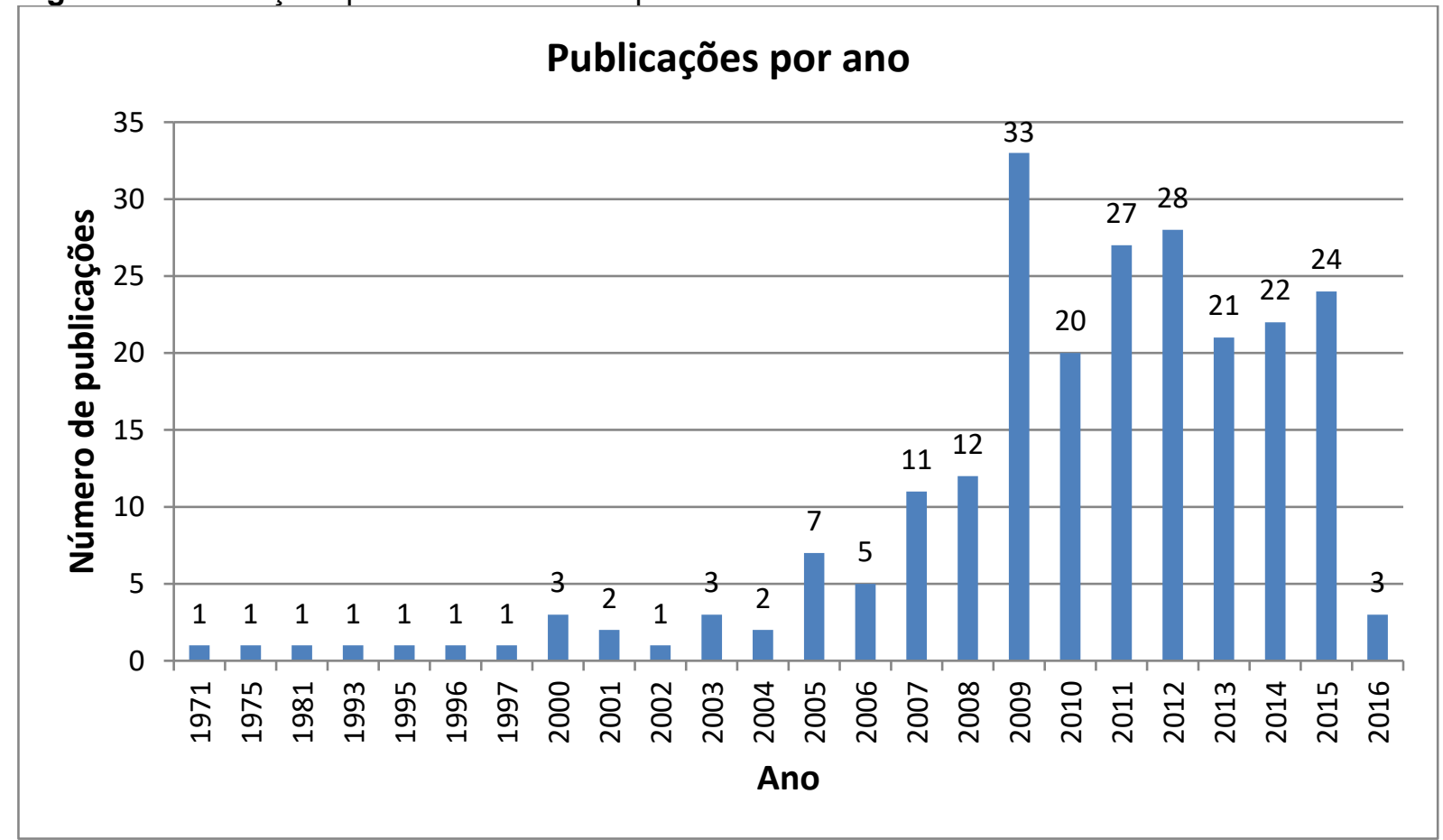

Fonte: Adaptado da base de dados Scopus (2016) 
A base de dados Scopus trabalha com um histórico de publicações a partir de 1971. De acordo com a figura 1, que ilustra a pesquisa realizada na Scopus, é possível perceber o significativo número de publicações ( $87 \%$ da amostra) realizadas nos últimos 10 anos.

A figura 2 apresenta a quantidade de publicações por ano, relacionadas com o tema conforto térmico em salas de aula na base WOS.

Figura 2 - Publicações por ano na base WOS

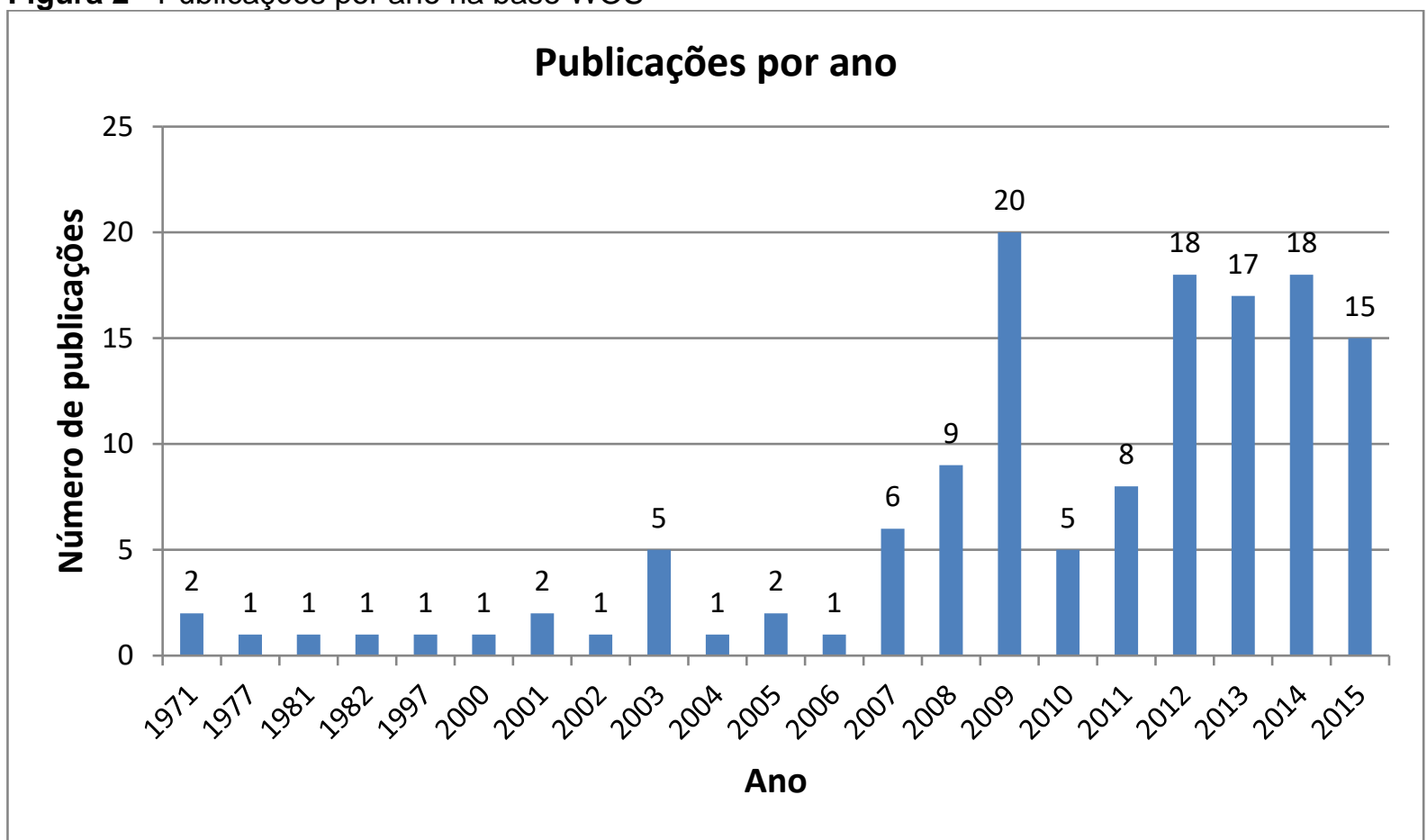

Fonte: Adaptado da base de dados WOS (2016)

Já a base de dados WOS trabalha com um histórico de publicações a partir de 1945. De acordo com a figura 2, também é possível perceber o significativo número de publicações ( $86 \%$ da amostra) realizadas nos últimos 10 anos.

Em ambas as bases de dados, notamos o aumento do número de publicações relacionadas ao tema na última década. $\mathrm{O}$ ano de 2009 inclusive teve o maior número de publicações tanto na Scopus quanto na WOS e em ambas as bases o número de publicações tem se mantido alto nos últimos anos, o que demonstra a emergência da temática conforto térmico em salas de aula, fato que pode estar associado aos temas que fazem relação com consumo de energia e eficiência energética. 


\subsection{Tipos de documentos que compõem as publicações}

Nas duas bases de dados, Scopus e WOS, os documentos compõem-se basicamente de artigos, 49,3\% e 68,1\% respectivamente, e de "papers" (Conference Paper, Proceedings Paper), $49 \%$ e $31,1 \%$ respectivamente. De certa forma isso demostra o caráter cientifico das publicações.

\section{4 Áreas temáticas das publicações}

O quadro 1 apresenta as cinco principais áreas temáticas das publicações relacionadas ao tema, de acordo com o número de publicações.

Quadro 1 - Áreas temáticas das publicações pesquisadas

\begin{tabular}{|c|c|c|c|}
\hline \multicolumn{2}{|c|}{ Base Scopus } & \multicolumn{2}{c|}{ Base WOS } \\
\hline Área temática & $\begin{array}{c}\text { Núm. de } \\
\text { publicações }\end{array}$ & Área temática & $\begin{array}{c}\text { Núm. de } \\
\text { publicações }\end{array}$ \\
\hline $\begin{array}{c}\text { Engineering } \\
\text { (Engenharia) }\end{array}$ & 149 & $\begin{array}{c}\text { Engineering } \\
\text { (Engenharia) }\end{array}$ & 82 \\
\hline $\begin{array}{c}\text { Environmental Science } \\
\text { (Ciência Ambiental) }\end{array}$ & 62 & $\begin{array}{c}\text { Construction Building } \\
\text { Technology } \\
\text { (Tecnologia da Construção) }\end{array}$ & 81 \\
\hline $\begin{array}{c}\text { Energy } \\
\text { (Energia) }\end{array}$ & 52 & $\begin{array}{c}\text { Energy Fuels } \\
\text { (Combustíveis Energéticos) }\end{array}$ & 36 \\
\hline $\begin{array}{c}\text { Social Sciences } \\
\text { (Ciências Sociais) }\end{array}$ & 43 & $\begin{array}{c}\text { Public Environmental } \\
\text { Occupational Health } \\
\text { (Saúde Ocupacional e } \\
\text { Ambiental Pública) }\end{array}$ & 17 \\
\hline $\begin{array}{c}\text { Computer Science } \\
\text { (Ciência da Computação) }\end{array}$ & 28 & $\begin{array}{c}\text { Thermodynamics } \\
\text { (Termodinâmica) }\end{array}$ & 14 \\
\hline
\end{tabular}

Fonte: Adaptado das bases de dados Scopus e WOS (2016)

Através do quadro 1 é possível perceber a diversidade de áreas temáticas em relação às publicações encontradas durante a pesquisa nas duas bases de dados. Porém, tanto na Scopus quanto na WOS, a área de Engenharia aparece em primeiro lugar, $64,5 \%$ e $60,7 \%$ respectivamente. Cabe ressaltar que na base WOS existem publicações classificadas em mais de uma área (campo) de pesquisa. 


\subsection{Título das fontes das publicações}

Os periódicos Building and Environment, Energy and Buildings e Indoor and Built Environment aparecem, respectivamente, nas $1^{\underline{a}}, 2^{\underline{a}}$ e $3^{\underline{a}}$ posições quanto ao número de publicações em ambas as bases de dados. Isso mostra a importância destes periódicos para pesquisas científicas relacionadas ao tema deste estudo. Além disso, considerando os dez primeiros periódicos em número de publicações, oito deles se repetem nas bases de dados Scopus e WOS, o que demostra a contribuição destas fontes para pesquisas relacionadas ao conforto térmico em salas de aula.

\subsection{Principais instituições dos autores dos trabalhos}

Em relação às instituições de ensino, há uma considerável diversidade entre as duas bases de dados, porém, a Universidade do Algarve (Portugal) aparece com o maior número de publicações na base Scopus e na base WOS. A University of Sidney (Austrália) que na base Scopus aparece em segundo lugar, também figura entre as principais instituições na base WOS. Outra instituição que também aparece entre as principais nas duas bases de dados é a University of Southampton (Reino Unido). Entre as universidades brasileiras, a Universidade Federal de Santa Catarina aparece à frente com 3 publicações na base Scopus e a Universidade Federal de Campina Grande com 2 publicações na base WOS.

\subsection{Idiomas e países das publicações analisadas}

O idioma inglês predomina massivamente nas publicações correspondentes ao resultado desta pesquisa. Na base Scopus são 221 publicações em inglês (95,6\%) e na base WOS são 130 publicações (96,2\%).

A China lidera o "ranking" de publicações em ambas as bases de dados. Isso reflete a preocupação deste país em relação ao conforto térmico em salas de aula, que neste caso possivelmente esteja relacionada às questões de eficiência energética e sustentabilidade, já que o país é uma das grandes potências mundiais. De acordo com um relatório da Climate Policy Initiative, atualmente a China procura equilibrar as tradições de baixa energia com melhorias no conforto e nos serviços, sendo que o 
maior potencial deste país para a economia de energia está no sentido de garantir elevados padrões de eficiência energética para as novas construções (AMECKE et al., 2013).

Pasa et al. (2012) lembram que o conhecimento das características construtivas da edificação e das características climáticas locais permite uma préavaliação do nível de conforto ambiental e do consumo de energia elétrica que será necessário para o uso da mesma.

Alguns países da Europa também influenciam densamente no número de publicações. Este resultado demonstra a importância dada por esta região aos efeitos do conforto térmico em prédios e construções escolares ou universitárias.

No "ranking" de publicações relacionadas ao tema pesquisado, o Brasil ocupa a $12^{\underline{a}}$ posição na base Scopus, com 7 trabalhos, e a $10^{\underline{a}}$ posição na base WOS, com 5 trabalhos.

\subsection{Principais autores das publicações}

Através da análise, observou-se um grande número de autores para os trabalhos realizados, visto que apenas uma pequena parcela destes autores publicou um número mais elevado de artigos sobre o tema. Essa constatação vem ao encontro do que comenta Guedes e Borschiver (2005) ao apresentar a Lei de Lotka, relacionada à produtividade dos autores e fundamentada na premissa que alguns pesquisadores publicam muito e muitos publicam pouco. Os autores Eusébio Z. E. Conceição e Maria Manuela J. R. Lúcio, ambos da Universidade do Algarve em Portugal, aparecem em $1^{\circ}$ e $2^{\circ}$ lugares, respectivamente, tanto na base Scopus quanto na base WOS.

Eusébio Z. E. Conceição é Doutor em Engenharia Mecânica, na especialidade de Aerodinâmica e é professor auxiliar do Departamento de Ciências da Terra, Mar e do Ambiente da Universidade do Algarve. Possui trabalhos e pesquisas relacionados ao conforto e qualidade do ar, energias renováveis, modelagem do comportamento térmico de edifícios, eficiência energética em edifícios, entre outros.

Um fato que merece destaque e que pôde ser analisado na base Scopus é que apesar de estar em $3^{\circ}$ lugar quanto ao número de publicações encontradas na pesquisa realizada, o autor Richard de Dear possui um índice h ( $h$-index) 28. Ou seja, na base Scopus este autor possui atualmente 28 publicações que já receberam ao 
menos 28 citações, excluindo as autocitações. Numa comparação com o autor Eusébio Z. E. Conceição, o mesmo possui um $h$-index 7 , de acordo com a base Scopus.

Richard de Dear é PhD em Climatologia Aplicada pela University of Queensland e é professor e diretor inaugural do Laboratório de Qualidade Ambiental Interior da University of Sidney. Concentra sua carreira de pesquisa na definição do que os ocupantes desejam e precisam dos seus ambientes construídos, avaliando o desempenho dos edifícios em termos de atender a esses requisitos. Dentro desse campo de pesquisa, é seu modelo adaptativo de conforto térmico que teve o maior impacto, não apenas na comunidade de pesquisa, mas também no projeto e operação de edifícios reais.

\subsection{Relação dos trabalhos com maior número de citações}

Através da análise realizada, verificou-se que entre as dez publicações com maior número de citações, cinco delas se repetem para as bases Scopus e WOS.

O quadro 2 apresenta as cinco publicações mais citadas levando em conta 0 número de citações tanto da base Scopus quanto da base WOS, referente a pesquisa realizada quanto ao tema deste estudo.

Quadro 2 - "Ranking" das publicações em número de citações nas bases Scopus e WOS

\begin{tabular}{|c|c|c|}
\hline № & Título / Autor / Periódico / Ano & $\begin{array}{l}\text { Número de } \\
\text { citações }\end{array}$ \\
\hline 1 & $\begin{array}{l}\text { Ventilation impact of a solar chimney on indoor temperature fluctuation } \\
\text { and air change in a school building } \\
\text { Khedari, J., Boonsri, B., Hirunlabh J. } \\
\text { Energy and Buildings, } 32 \text { (1), p. 89-93, } 2000\end{array}$ & 134 \\
\hline 2 & $\begin{array}{l}\text { Perception of the thermal environment in high school and university } \\
\text { classrooms: Subjective preferences and thermal comfort } \\
\text { Corgnati, S.P., Filippi, M., Viazzo S. } \\
\text { Building and Environment, } 42 \text { (2), p. } 951-959,2007\end{array}$ & 106 \\
\hline 3 & $\begin{array}{l}\text { Thermal comfort in classrooms in the tropics } \\
\text { Wong, N.H., Khoo, S.S. } \\
\text { Energy and Buildings, } 35 \text { (4), p. } 337-351,2003\end{array}$ & 102 \\
\hline 4 & $\begin{array}{l}\text { Shading effect on long-term outdoor thermal comfort } \\
\text { Lin, T.P., Matzarakis A., Hwang R.L. } \\
\text { Building and Environment, } 45 \text { (1), p. } 213-221,2010\end{array}$ & 99 \\
\hline 5 & $\begin{array}{l}\text { Winter indoor air quality, thermal comfort and acoustic performance of } \\
\text { newly built secondary schools in England } \\
\text { Mumovic, D., Palmer, J., Davies, M., Orme, M., Ridley, I., Oreszczyn, T., } \\
\text { Judd, C., Critchlow, R., Medina, H.A., Pilmoor, G., Pearson, C., Way P. } \\
\text { Building and Environment, } 44 \text { (7), p. } 1466-1477,2009\end{array}$ & 88 \\
\hline
\end{tabular}

Fonte: Adaptado das bases de dados Scopus e WOS (2016) 
Uma das finalidades de realizar uma pesquisa referente aos trabalhos com maior número de citações é verificar a relação das publicações mais citadas com os autores que mais publicaram.

Nota-se que em ambas as bases de dados, os autores das publicações mais citadas não estão entre os autores que mais publicaram sobre este tema especificamente. Isso pode estar relacionado com o tipo de documento, papers, por exemplo, e também com os periódicos cujos trabalhos destes autores estão publicados.

Outra questão importante quanto à análise de citações é o Fator de Imediatismo ou de Impacto. A proposição é, em determinada área científica, artigos de periódicos citados com mais frequência são mais relevantes que artigos menos citados, no entanto, é necessário haver um cuidado no uso demasiado deste conceito (GUEDES e BORSCHIVER, 2005).

Cabe lembrar também que em caso de interesse por parte do pesquisador que estiver utilizando as bases de dados Scopus e WOS, é possível consultar todas as publicações que citam os respectivos artigos apresentados no quadro 2 .

\subsection{Análise dos trabalhos com maior número de citações}

Nesta etapa foram analisados os seis trabalhos com maior número de citações, no intuito de constatar alguns tópicos relevantes ao tema, os principais resultados das pesquisas e averiguar possíveis semelhanças entre estes resultados. Entre os seis trabalhos analisados, três deles aparecem com o maior número de citações tanto na base Scopus quanto na base WOS.

Analisando os principais resultados dos trabalhos com maior número de citações é possível perceber uma estreita relação entre os tópicos conforto térmico e ventilação. Uma hipótese para relação dos tópicos é o grande número de escolas e instituições de ensino que não usufruem de um sistema de condicionamento de ar. Outra hipótese é a crescente preocupação de países e governos com sistemas que possam ocasionar o aumento do consumo de energia e com isso prejudicar os padrões energéticos ou ir de encontro a programas de sustentabilidade e eficiência energética. 
Nos estudos avaliados, a ventilação dos ambientes é alcançada naturalmente ou por meio de sistemas mecânicos. Para as investigações, diversos trabalhos adotam medições in loco e modelos já conhecidos para o estudo do conforto térmico, como por exemplo o modelo proposto por Fanger, do voto médio predito (PMV), no intuito de avaliar subjetivamente a sensação térmica dos indivíduos envolvidos. Porém, em muitos casos, os autores acabam constatando algumas divergências entre a teoria e a prática no que se refere a pessoas que se julgam termicamente confortáveis em determinados ambientes escolares.

Como considerações relevantes destes estudos que avaliaram essencialmente ambientes sem ar condicionado podemos destacar o desenvolvimento de um gráfico do conforto com ventilação, proposto para o clima tailandês (KHEDARY, et al., 2000) e também uma discrepância entre a zona de conforto prevista pela ASHRAE 55 e a faixa de temperatura aceita pelos ocupantes de uma escola secundária, sem ar condicionado, em Singapura. No estudo realizado por Wong e Khoo (2003), os ocupantes encontraram uma faixa aceitável de temperatura que fica além da zona de conforto admissível pela norma.

Estudos realizados por Corgnati et al. (2007) em salas de aula de ensino médio e salas universitárias em Torino na Itália, também mostraram um desacordo entre o PPD medido e o percentual de insatisfeitos a partir dos questionários. Neste caso, os ocupantes também aceitaram valores de temperatura acima do previsto na norma americana que estabelece as condições ambientais térmicas para ocupação humana.

Como tanto o estudo de Singapura quanto o realizado na Itália tinham como objetivo conhecer as condições térmicas nas salas de aula por meio de medições objetivas e comparar com o modelo previsto pela norma ASHRAE 55, podemos pressupor que é necessário haver um cuidado ao se tomar medidas para climatização de ambientes escolares que tomem como base a norma (escala) ASHRAE 55 na avaliação das condições de conforto térmico.

Outro fato averiguado e que é destacado por alguns autores dos trabalhos analisados é a investigação das condições de qualidade do ar em salas de aula e ambientes de estudo, uma vez que este fato pode interferir consideravelmente no rendimento e no bem estar dos alunos. Em muitos países há uma crescente preocupação sobre a qualidade do ar nas escolas, já que poluentes atmosféricos produzidos por fontes externas afetam o meio ambiente e a nossa saúde. A qualidade 
do ar nas salas de aula é de especial preocupação para os estudantes, particularmente àqueles mais sensíveis a má qualidade do ar (JURADO, et al., 2014)

Ainda assim, D. Mumovic et al. (2008) destacam que a qualidade do ar interior por si só não é suficiente para proporcionar um bom ambiente de aprendizagem. Conforto térmico e desempenho acústico também são aspectos vitais das condições internas. Em seus estudos na Inglaterra, o grupo concluiu que a complexa interação entre ventilação e o conforto térmico e acústico apresenta consideráveis desafios para os projetistas. O trabalho mostrou que, de acordo com os padrões acústicos exigidos, foi possível alcançar designs de ventilação natural que mantivessem o nível de ruído interno adequado, quando o nível de ruído externo não fosse excessivo, e que a maioria das salas de aula da amostra atendeu ao requisito de limitar a concentração média diária de $\mathrm{CO}_{2}$ abaixo de 1500ppm.

Os demais estudos analisados não apresentaram tópicos comuns que estivessem relacionados ao tema central deste trabalho, porém, também apresentaram investigações que objetivaram discutir ações de conforto térmico em salas de aula. Na Tailândia foi proposto, por meio de uma pesquisa experimental, averiguar a viabilidade de uma chaminé solar para reduzir o ganho de calor em uma sala, através da indução de ventilação natural e do efeito das aberturas (porta, janela e entrada da chaminé solar) sobre a taxa de ventilação (KHEDARY, et al., 2000). Já em Taiwan, foram realizados 12 experimentos para analisar as condições térmicas ao ar livre em um campus universitário (LIN, et al., 2010).

\section{CONSIDERAÇÕES}

Através deste estudo foi possível verificar que o tema conforto térmico em salas de aula está em evolução, já que em ambas as bases de dados pesquisadas verificouse que o número de publicações aumentou consideravelmente nos últimos 10 anos. As publicações encontradas durante a pesquisa são em sua maioria artigos científicos e a maior parte está relacionada a área de Engenharia. Entre os periódicos com maior número de publicações destacam-se o Building and Environment, o Energy and Buildings e o Indoor and Built Environment. Entre as instituições que mais publicaram trabalhos relacionados ao tema pesquisado destacam-se a Universidade do Algarve e a University of Sidney. 
No "ranking" dos países que mais publicam sobre a temática a China lidera nas duas bases. Na base Scopus, os Estados Unidos é o segundo país que mais publica, seguido por Portugal, Reino Unido e Austrália. Na WOS, a Inglaterra é o segundo país que mais publica, seguido por Portugal, Itália e Estados Unidos. O Brasil ocupa a $12^{\underline{a}}$ posição na base Scopus e a $10^{a}$ posição na base WOS.

Através de análise realizada entre as publicações com maior número de citações e os autores que mais publicaram sobre este tema foi possível verificar que, ao menos em sua maioria, as publicações com o maior número de citações não pertencem aos autores que mais publicam sobre o mesmo tema. Também foi possível constatar uma relação entre o tema pesquisado e os tópicos ventilação, qualidade do ar interior e conforto ambiental e de forma mais superficial, consumo de energia e eficiência energética.

Com a realização deste trabalho foi possível constatar a proficuidade de ferramentas de busca como a Scopus e a WOS para a realização de pesquisas acadêmicas. Neste estudo, os resultados apresentaram uma grande similaridade, o que de certa forma demonstra a credibilidade destas bases para que a comunidade acadêmica possa buscar informações sobre determinado tema e investigar algumas peculiaridades relacionadas à produção científica do mesmo. Neste sentido, uma pesquisa bibliométrica pode apresentar um grande benefício a futuros pesquisadores na busca de subsídios relacionados ao tema no qual desejam realizar suas pesquisas e revisões bibliográficas.

Uma limitação deste estudo é a utilização de apenas duas bases de dados específicas. Por isso, para futuros estudos que utilizarem esta metodologia sugere-se a pesquisa em maior amplitude, utilizando outras bases de dados e bases nacionais, por exemplo.

Outra sugestão é a realização de novas pesquisas bibliométricas com temas relacionados à área de Engenharia, já que verificou-se esta carência durante este estudo.

\section{REFERÊNCIAS}

AMECKE, H. et al. Buildings Energy Efficiency in China, Germany and the United States.

Climate Policy Initiative, abr. 2013. 28p. (CPI Report). 
ASHRAE. 2009. ASHRAE Handbook - Fundamentals. American national standards institute; American society of heating, refrigerating and air-conditioning engineers. Atlanta, Georgia. 2009.

ASHRAE STANDARD 55 - 2013. Thermal Environmental Conditions for Human Occupancy. Atlanta, Georgia: American Society of Heating Refrigerating and AirConditioning Engineers, 2013

BARBHUIYA, S.; BARBHUIYA, S. Thermal comfort and energy consumption in a UK educational building. Building and Environment, v.68, p. 1-11, 2013. https://doi.org/10.1016/j.buildenv.2013.06.002

BATIZ, E. C. et al. Avaliação do conforto térmico no aprendizado: estudo de caso sobre influência na atenção e memória. Produção, v. 19, n. 3, p. 477-488, 2009.

CHUEKE, G. V.; AMATUCCI, M. O que é bibliometria? Uma introdução ao fórum. Revista Eletrônica de Negócios Internacionais, v.10, p. 1-5, mai./ago. 2015.

CORGNATI, Stefano Paolo; FILIPPI, Marco; VIAZZO, Sara. Perception of the thermal environment in high school and university classrooms: subjective preferences and thermal comfort. Building and Environment, v.42, p.951-959, 2007.

https://doi.org/10.1016/i.buildenv.2005.10.027

COUTINHO FILHO, E. F. et al. Avaliação do conforto térmico ambiental em uma escola municipal de João Pessoa. In: ECONTRO DE EXTENSÃO UNIVERSITÁRIA. DESAFIOS DA INDISSOCIABILIDADE ENTRE ENSINO E EXTENSÃO, 9. 2007, João Pessoa: Editora Universitária/UFPB, 2007. Disponível em:

$<$ http://www.prac.ufpb.br/anais/IXEnex/extensao/documentos/anais/5.MEIOAMBIENTE/5CT DEPPEX01.pdf>. Acesso em: 07 jan. 2016.

FROTA, A. B.; SCHIFFER, S. R. Manual do conforto térmico. 7ª Edição - São Paulo: Studio Nobel, 2003.

GUEDES, V.; BORSCHIVER, S. Bibliometria: uma ferramenta estatística para a gestão da informação e do conhecimento, em sistemas de informação, de comunicação e de avaliação científica e tecnológica. In: CINFORM - ENCONTRO NACIONAL DE CIÊNCIA DA INFORMAÇÃO, 6., 2005, Salvador. Anais... Salvador: ICI/UFBA, 2005.

HAVERINEN-SHAUGHNESSY, U.; SHAUGHNESSY, R. J. Effects of classroom ventilation rate and temperature on students' test scores. Plos One, v.10 (8), p. 1-14, ago. 2015.

HIRSCH, J. E. An index to quantify an individual's scientific research output. Proceedings of the National Academy of Sciences of the United States of America, v. 102, n. 46, p. 16569-16572, 2005. https://doi.org/10.1073/pnas.0507655102

International Organization for Standardization (ISO). ISO 7730:2005 - Ergonomics of the thermal environment - Analytical determination and interpretation of thermal comfort using calculation of the PMV and PPD indices and local thermal comfort criteria; 2005.

JURADO, S. R.; BANKOFF, A. D. P.; SANCHEZ, A. Indoor air quality in brazilian universities. International Journal Environmental Research and Public Health, v. 11, p.7081-7093, 2014. https://doi.org/10.3390/ijerph110707081 
KHEDARI, J.; BOONSRI, B.; HIRUNLABH, J. Ventilation impact of a solar chimney on indoor temperature fluctuation and air change in a school building. Energy and Buildings, v.32, p.89-93, 2000. https://doi.org/10.1016/S0378-7788(99)00042-0

KHEDARI, J. et al. Thailand ventilation comfort chart. Energy and Buildings, v.32, p.245249, 2000. https://doi.org/10.1016/S0378-7788(00)00050-5

KRUGÜER, E. L.; ZANNIN, P. H. T. Acoustic, thermal and luminous comfort in classrooms. Building and Environment, v.39, p. 1055-1063, 2004.

LAMBERTS, R.; DUTRA, L.; PEREIRA, F. O. R. Eficiência energética na arquitetura. 3. ed. Rio de Janeiro: Eletrobrás/Procel, 2014. Disponível em:

$<$ http://www.labeee.ufsc.br/sites/default/files/apostilas/eficiencia_energetica_na_arquitetura.p df>. Acesso em: 12 jan. 2016

LIN, T.; MATZARAKIS, A.; HWANG, R. Shading effect on long-term outdoor thermal comfort. Building and Environment, v.45, p. 213-221, 2010.

https://doi.org/10.1016/i.buildenv.2009.06.002

MUMOVIC, D. et al. Winter indoor air quality, thermal comfort and acoustic performance of newly built secondary schools in England. Building and Environment, v.44, p. 1466-1477, 2008. https://doi.org/10.1016/j.buildenv.2008.06.014

NICO, M. A.; LIUZZI, S.; STEFANIZZI, P. Evaluation of thermal comfort in university classrooms through objective approach and subjective preference analysis. Applied Ergonomics, v.48, p.111-120, 2015. https://doi.org/10.1016/j.apergo.2014.11.013

PASA, C. C. M. U. et al. Avaliação da eficiência energética em edificações e sua relação com os materiais construtivos empregados. Revista Produção Online, v.12, n. 1, p.229247, 2012. https://doi.org/10.14488/1676-1901.v12i1.873

SARBU, I.; PACURAR, C. Experimental and numerical research to assess indoor environment quality and schoolwork performance in university classrooms. Building and Environment, v.93, p. 141-154, 2015. https://doi.org/10.1016/i.buildenv.2015.06.022

WONG, N. H.; KHOO, S. S. Thermal comfort in classrooms in the tropics. Energy and Buildings, v.35, p.337-351, 2003. https://doi.org/10.1016/S0378-7788(02)00109-3

YATIM, S. R. M. et al. Thermal comfort in air-conditioned learning environment. In: INTERNATIONAL SYMPOSIUM \& EXHIBITION IN SUSTAINABLE ENERGY \& ENVIRONMENT, 3., 2011, Melaka. Estados Unidos: IEEE, 2011. Disponível em: $<$ http://ieeexplore.ieee.org/xpl/login.jsp?tp=\&arnumber=5977088\&url=http\%3A\%2F\%2Fieeex plore.ieee.org\%2Fiel5\%2F5955057\%2F5977077\%2F05977088.pdf\%3Farnumber\%3D59770 88>. Acesso em: 06 jan. 2016

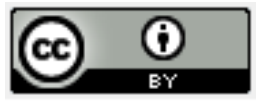

Artigo recebido em01/09/2017 e aceito para publicação em 24/05/2018 DOI: http://dx.doi.org/10.14488/1676-1901.v18i3.2989 